IZA DP No. 9297

The Effectiveness of Policies that Promote Labor Force Participation of Women with Children:

A Collection of National Studies

Elizabeth U. Cascio

Steven J. Haider

Helena Skyt Nielsen

August 2015 


\title{
The Effectiveness of Policies that Promote Labor Force Participation of Women with Children: A Collection of National Studies
}

\author{
Elizabeth U. Cascio \\ Dartmouth College and IZA \\ Steven J. Haider \\ Michigan State University and IZA \\ Helena Skyt Nielsen \\ Aarhus University and IZA
}

Discussion Paper No. 9297

August 2015

\author{
IZA \\ P.O. Box 7240 \\ 53072 Bonn \\ Germany \\ Phone: +49-228-3894-0 \\ Fax: +49-228-3894-180 \\ E-mail: iza@iza.org
}

Any opinions expressed here are those of the author(s) and not those of IZA. Research published in this series may include views on policy, but the institute itself takes no institutional policy positions. The IZA research network is committed to the IZA Guiding Principles of Research Integrity.

The Institute for the Study of Labor (IZA) in Bonn is a local and virtual international research center and a place of communication between science, politics and business. IZA is an independent nonprofit organization supported by Deutsche Post Foundation. The center is associated with the University of Bonn and offers a stimulating research environment through its international network, workshops and conferences, data service, project support, research visits and doctoral program. IZA engages in (i) original and internationally competitive research in all fields of labor economics, (ii) development of policy concepts, and (iii) dissemination of research results and concepts to the interested public.

IZA Discussion Papers often represent preliminary work and are circulated to encourage discussion. Citation of such a paper should account for its provisional character. A revised version may be available directly from the author. 
IZA Discussion Paper No. 9297

August 2015

\section{ABSTRACT \\ The Effectiveness of Policies that Promote Labor Force Participation of Women with Children: A Collection of National Studies}

Numerous countries have enacted policies to promote the labor force participation of women around the years of childbearing, and unsurprisingly, many research articles have been devoted to evaluating their effectiveness. Perhaps more surprisingly, however, six such articles were submitted independently over several months to Labour Economics and subsequently made it through the normal review process. These articles are collected in the Special Section that follows. This article provides additional background to facilitate the understanding of the policies that are evaluated in the Special Section articles and, more importantly, a discussion of what can be learned from the articles as a collection. Taken together, the articles are quite informative in demonstrating how the effectiveness of policies can vary across different national contexts and how this variation itself can be usefully examined with the standard theoretical framework.

JEL Classification: J13, J22

Keywords: childcare, parental leave

Corresponding author:

Helena Skyt Nielsen

Department of Economics and Business

Aarhus University

Fuglesangs Allé 4

DK-8210 Aarhus V

Denmark

E-mail: hnielsen@econ.au.dk 


\section{Introduction}

Policymakers and researchers have been interested in the determinants of female labor force participation (LFP) for decades. Given the costs of childbearing and of caring for young children and often deeply entrenched gender roles, women face impediments to realizing their labor market potential that men do not. It is therefore not surprising that these costs - and policies designed to alleviate them - have become a focal point in this discussion.

These costs and policies have varied considerably both across countries and over time. The presumable outcome of this variation is reflected in Figure 1, which plots the ratio of female to male LFP for 25 to 54 year olds - an age range typical for bearing and rearing children - for a collection of OECD countries between 2000 and $2014 .{ }^{1}$ The figure shows substantial variation across countries in the LFP rates of women in this age range, particularly early in the period. In 2000 , for instance, LFP rates among female 25 to 54 year olds in Japan and Spain were less than $70 \%$ of those of their male counterparts; in Denmark, by contrast, relative female LFP stood at over $90 \%$ at this time. Over the past decade and a half, the across-country variation has diminished substantially. By 2014, many countries that were initially lagging behind Denmark not just Japan and Spain, but also the Netherlands, Canada, France, and Germany - have largely converged.

While this convergence likely has many explanations, it is notable that each of these six countries expanded benefits for young families over the last several decades as well. These reforms to family policy have varied across countries and have been wide-ranging in scope, encompassing expansions of guaranteed paid leave around childbearing, increased subsidies for

\footnotetext{
${ }^{1}$ Using the relative female LFP rate is intended to abstract from differences across countries in the LFP rate for males and females alike.
} 
childcare, and the provision of early education for children of preschool age (children ages 3 to 5 for our purposes here). By 2011 (the most recent year with data available), the average country in this group of six spent about $1.8 \%$ of its GDP on these programs, up from about $1.5 \%$ in 2000 and 1.2\% in 1990 (OECD Social Expenditure Database 2014). While a central goal of these programs has been to promote healthy child development, another important goal has been to make it easier for women to combine work and family obligations.

The labor supply effects of these reforms are the subject of the articles in the Special Section of this edition of Labour Economics. These papers were not submitted in response to a call for papers, but rather were independently submitted by the various authors over several months. All articles adopt a transparent reduced-form identification strategy, with one article (Geyer, Haan, and Wrohlich, 2015) gaining additional insights through more structural methods. While most of the articles focus on fairly short-run labor supply effects of a given policy change, one article explicitly tackles the very difficult question of long-run labor supply effects (Haeck, Lefebvre, and Merrigan, 2015).

This article provides some additional background to facilitate the understanding of the policies that are evaluated in the Special Section articles and, more importantly, a discussion of what can be learned from the articles as a collection. We begin by providing an overview of the policies that they evaluate, highlighting the variation in policy "bundles" across countries. We next describe the theoretical effects of policy changes, with an emphasis on how the policies might interact with one another and with the pre-existing female LFP rate. We then provide an overview of the articles themselves before concluding with some speculation about the sources 
of variation in findings across countries and what they imply for the direction of future research.

\section{Overview of the Policies}

As described above, the articles in the Special Section of this issue evaluate three different types of policies that have the potential to affect the labor supply of mothers with young children: leave policies, subsidized childcare, and formal preschool. We begin by describing each of these policies and then consider their potential interactions.

\subsection{Leave Policies}

Leave policies, broadly speaking, provide new mothers (and sometimes fathers) time off from work to care for infants without job loss and usually with some extent of income replacement. Such policies exist in some form in all OECD countries. In addition to promoting the health of new mothers and their children, leave assists parents in managing employment obligations when young children are present. ${ }^{2}$ In some countries, distinct policies target different familial stages (pregnancy, newborn care, and later childcare) and different caregivers (the mother and the father), whereas other countries have adopted more integrated policies.

Despite the breadth of these policies, they can be usefully broken down into four types. The first is maternity leave, which is employment-protected leave granted to a woman around the time of childbirth. Almost all OECD countries pair this employment-protected leave with income support payments. The second type is paternity leave, which is employment-protected leave granted to fathers around the time of childbirth. Paternity leave is usually also

\footnotetext{
2 This section draws heavily on OECD (2015). See that excellent article for a more complete discussion of the relevant policies and how they interact, as well as a detailed description of these policies for OECD countries.
}

p. 3 
accompanied by income support payments, but tends to be far shorter than maternity leave.

The third type is parental leave, which again is employment-protected leave, often accompanied by income support payments, granted to parents to care for older infants. ${ }^{3}$ The fourth type is home care leave, which again is employment-protected leave, but follows parental leave. When available, home leave can extend the time in which parents care for a child for another year or two, but is generally not accompanied by income support. Home leave is much less common than the other types of leave among OECD countries.

Table 1 provides information about the generosity of paid, employment-protected leave programs in 2014 averaged across the 33 OECD countries and for the nine OECD countries included in Figure 1 - the six countries represented in the Special Section and three countries that have been analyzed in previous studies, the United States, the United Kingdom, and Denmark. On average, OECD countries provide 17 weeks of paid maternity leave, accompanied by an income support payment that replaces $77.7 \%$ of a woman's gross earnings (i.e., an earnings replacement rate of $77.7 \%$ ). On average, women may then take an additional 36.6 weeks of paid parental and home care leave at a $45.8 \%$ replacement rate. Paid leave reserved for the father, either through paternity leave or parental leave, is much less generous, covering on average 9.0 weeks of leave at a replacement rate of $64.2 \%$.

With the notable exception of the United States, each of the individual countries listed in Table 1 provides some form of paid leave. ${ }^{4}$ However, there is tremendous cross-country

\footnotetext{
${ }^{3}$ Parental leave is often in addition to maternity and paternity leave and, in some cases, completely integrated with the two. In many cases, parental leave is "sharable" between the two parents in terms of claiming and/or timing.

${ }^{4}$ The United States federally mandates 12 weeks of unpaid leave through the Family and Medical Leave Act, which many states have chosen to expand. In addition, six states and the District of Columbia provide for some sort of paid maternity leave.
} 
variation in the breadth and generosity of these programs. For example, while the Special Section countries all tend to have maternity leave benefits that are tightly clustered around the OECD average, both in terms of the number of weeks allowed and in terms of income replacement rates, the variability in later paid leave available to the mother is greater. In Spain, for example, no such leave is available. There is also tremendous variability in the paid leave reserved for the father, with Canada having no such reserved leave (although fathers can share the parental leave). Also of note is Japan, which has one of the most generous leave policies available to both the mother ( 44 weeks at a replacement rate of $59.9 \%$ ) and the father (52 weeks at a replacement rate of $58.4 \%)$.

There is no mandate that new parents take advantage of leave policies, and indeed, there is much variation in take-up across countries. For example, in France in $2011,97 \%$ of eligible women took maternity leave and $66 \%$ of eligible men took paternity leave, whereas in Denmark, the corresponding rates were $99 \%$ for mothers and $89 \%$ for fathers (OECD 2015). In Japan - which has extremely generous leave programs, as noted above - the take-up rate for parental leave by mothers was $72 \%$ and by fathers was only $0.5 \%$ for children born in $2006-07$ (OECD 2015).

\subsection{Childcare Subsidy Policies}

After parents return to work, many countries continue to provide support by subsidizing the costs of privately-provided (but generally regulated) family-based or center-based childcare. These subsidies can come in many forms, including direct payments to childcare agencies that reduce the out-of-pocket costs to parents, refunds or rebates directly to the parents, and favorable tax treatment of childcare costs. These subsidies can vary by family type and 
earnings and by the type of childcare arrangement. Importantly, just because childcare slots are subsidized does not necessarily imply that slots are available, or that available (or newly available) slots are of a specified type or quality. This issue is important in several of the national contexts discussed below.

To demonstrate the variation in the generosity of childcare policies, Table 2 lists net (of all subsidies) childcare costs for our nine focal countries. ${ }^{5}$ (For some countries, the data unfortunately refer to only one area within a country; when applicable, this area denoted in parentheses beside the country name.) While these net costs will also reflect differences across countries in market conditions, childcare quality, and childcare regulations, they still reflect the net cost for a parent to provide formal childcare so that she can go to work. The table lists these net costs as the monthly fulltime childcare costs for two children ages 2 and 3 , expressed as a fraction of monthly earnings, for a hypothetical dual-earner family and a hypothetical sole-parent family. The dual-earner family is assumed to earn a joint wage that is $150 \%$ of the average wage with both parents working fulltime, and the sole-parent family is assumed to earn $50 \%$ of the average wage, also working fulltime; fulltime for childcare and working is assumed to be 40 hours/week. Although these calculations may be an upper bound on the childcare cost burden for the typical family because many families will not have young children spaced so closely and may take advantage of more informal arrangements or part-time care, the variation across countries should nevertheless still be informative regarding cost variation.

${ }^{5}$ All of these costs are taken directly from OECD (2014).

p. 6 
For the hypothetical dual-earner family, the average net childcare costs across OECD countries are $17.1 \%$ of earnings. Thus, on average, almost one-fifth of earnings for families with two children are devoted to childcare. These net costs vary tremendously across the Special Section countries, ranging from a low of 7.9\% in Spain to 31.2\% in Canada (Ontario); notably, childcare costs are much lower in Québec, whose $\$ 5 /$ day universal childcare policy is the subject of Haeck, Lefebvre, and Merrigan (2015) in the Special Section. Among the other countries listed, Denmark is among the least expensive (11.9\%) and the United Kingdom and the United States (Michigan) are among the most expensive (45.0 and 39.7\%, respectively).

Turning to the costs for a hypothetical sole-parent family in Table 2, we generally find that the costs are lower than those for dual-earner families, consistent with more generous subsidies for low-earnings households, or means-testing. For the sole-parent family, the average net childcare cost among OECD countries is $9.8 \%$ of earnings. Childcare costs are completely subsidized in Denmark for these sole-parent households and almost completely subsidized in France and Germany (Hamburg). Yet, the childcare cost burden for single-earner families is about the same as that for dual-earner families in Canada (Ontario) and the United States (Michigan), equal to about one third of earnings.

\subsection{Preschool Programs}

Closely related to childcare subsidy policies are public preschool programs. Since they have similar effects on maternal labor supply in theory, as we describe below, there is not always a clear distinction between the two in the literature. In practice, however, several important distinctions exist. First, preschool programs are generally publicly provided, sometimes directly through or in cooperation with a country's public school system. As a result, families bear little 
direct cost of enrollment, save perhaps the cost of meals and possibly uniforms, whereas childcare expenses can be reimbursed ex post. Second, preschool programs usually target older children, often ages 3 to 5, typically target younger children as well. Third, given the focus on older children, these programs often have an educational focus.

In some cases, preschool programs can usefully be thought of as a downward extension of the existing public school system: They offer the same (essentially free) childcare implicit in public education for older children to families with younger children. ${ }^{6}$ As is the case with public education, these programs are generally universal, available to all children who meet the age criteria. This makes for another important distinction from subsidized childcare, which may have constraints on availability. Some public preschool programs are be targeted, for example, on the basis of family income; such preschool programs are common in the United States.

With that said, the distinction between childcare and preschool is not always clear, and consequently, Table 3 provides fulltime enrollment rates for 3-, 4-, and 5-year-olds in formal childcare and preschool combined, as calculated by the OECD. ${ }^{7}$ On average for the OECD countries, enrollment rates increase with age, becoming nearly universal by age 5 (the enrollment rates are $63.0 \%, 82.4 \%$, and $92.1 \%$ for $3-, 4-$, and 5 year-olds, respectively). Among our focal countries, many of the European countries - including those represented in the Special Section - have very high enrollment rates even for 3- and 4-year-olds. For example, the 3-year-old enrollment rates are 100\% for France, 88.0\% for Germany, 98.3\% for Spain, and 96.7\% for Denmark, and the 4-year-old enrollment rates for all of these countries are above

\footnotetext{
${ }^{6}$ This is sometimes reflected in the hours that public preschool is provided: As is the case with public schooling of older children, even "full-day" programs may not provide childcare coverage for a full day of work.

${ }^{7}$ Fulltime enrollment rates are calculated as fulltime equivalents (FTEs), where fulltime is considered to be 30 hours/week. See the OECD Family Database Table PF3.2.A for additional details about how these enrollment rates were constructed.
} 
95\%. Canada, the United States, and the Netherlands (at least for 3-year-olds) are outliers in enrollment for this age range. In the United States, for example, public education is universally available for 5-year-olds, but public preschool programs are not widely available for 4-year-olds and are very rare for 3 -year-olds. ${ }^{8}$ The age profile of enrollment rates for Canada (inclusive of all provinces) is even steeper.

\subsection{Variation in Policy "Bundles" and in Female LFP}

Comparing the figures in Tables 1 through 3, we see that it is not always the case that countries with the more generous leave policies also have more generous childcare subsidies or public preschool programs. It is true that Denmark is generous on all three accounts, and the United States is not. However, the extremely generous Japanese leave policy is not matched by similarly generous childcare subsidies for younger children. By contrast, though Spain is relatively limited in terms of leave policies, it has very generous childcare subsidies and universal preschool starting at age 3. As discussed in the coming sections, these policies interact with one another in theory and (presumably) in practice.

A casual comparison would suggest that the variation in policy environments shown in Tables 1 through 3 is correlated with the variation in relative female LFP depicted in Figure 1. For example, Denmark not only has particularly generous family policies among the countries of interest, but it also maintains the highest female LFP rate. In the later years shown in Figure 1, which correspond to the policies described in the tables, the United States has one of the

\footnotetext{
${ }^{8}$ There is significant heterogeneity in public preschool programs within the United States, however. For example, in 2011, three states (Georgia, Oklahoma, and West Virginia) had universal state-funded programs for 4-year-olds, but ten states had no program at all (Cascio and Schanzenbach, 2013). Most existing state programs in the United States for 3- and 4-year-olds are means-tested, like the well-studied federal U.S. preschool program, Head Start. However, it is worth noting that the figures shown in Table 3 include both private and public enrollment, and the United States has a relatively robust private early education sector.
} 
lowest rates of female LFP to match its relatively stingy family benefits. Of course, this is only suggestive evidence that these policies matter. Policy evaluations of the type included in the Special Section are needed to identify causal effects, and by drawing on a wide range of policy settings, the Special Section articles illuminate the importance of these policy interactions in practice.

In addition, even if family policy has helped to raise female LFP in the past, the labor supply effects of any new policy may not be large in a country where female LFP is already high. It is intuitive that effects on the extensive employment margin will be dampened when many mothers are already working. Furthermore, as discussed in the next section, mothers who would have already been working may in theory work less if childcare subsidies or public preschool programs are further expanded. Given the large degree of variation in female LFP across the countries they analyze, the Special Section articles can provide important insight into the role that pre-existing levels of LFP plays in family leave policy effectiveness.

\section{Theoretical Variation in Policy Effects}

Fortunately for researchers, the rich and varied policies described in the previous section have not remained constant over time. Changes have happened along many dimensions: leave policies in some countries have changed in duration, population coverage, and rate of income support; childcare subsidies have been expanded in size and scope; and preschool programs have been expanded to reach younger children and new populations. When harnessed in an appropriate econometric framework, policy changes such as these can provide valuable insights into how the costs of bearing and caring for children affect female LFP. While precise details 
will vary from case to case, standard static labor supply theory provides a useful framework for anticipating the effects of these reforms, and is thus useful to briefly discuss.

\subsection{Theoretical Background}

In a static labor supply framework, new mothers can "buy" an hour of time at home with an infant or young child - a use of time that only an economist would consider to be a form of leisure - by reducing consumption of goods and services. In the absence of government intervention, the price is the mother's hourly wage rate less the price per hour of childcare purchased outside of the home. In other words, the opportunity cost of another hour at home is foregone earnings net the expense of engaging a caregiver. All else equal, mothers who command higher wage rates should be more likely to return to work, and mothers who face higher childcare costs be less likely to return to work. Mothers with stronger preferences for home care should also engage in less market work, all else equal.

In theory, each of the policy changes described above will affect maternal labor supply by changing her budget constraint. As originally pointed out in the seminal work on U.S. kindergarten programs (universal preschool programs for 5-year-olds) by Gelbach (2002), the standard policy evaluation can only identify reduced-form effects on hours worked, averaging across the effects for mothers who would have been working in the policy's absence and for mothers who not have been. Such a policy evaluation was different from many of the preceding studies, which instead were focused on estimating elasticities of maternal employment with respect to wages and childcare costs using more structural methods. Moreover, such a policy evaluation can lead to more ambiguous theoretical predictions. 
Consider the introduction of a more generous childcare subsidy or a new public preschool program for a younger group of children. Though the former is explicit (cash) or and the latter is implicit (in kind), both are childcare subsidies from the perspective of the model. As such, they increase a mother's wage net of the cost of childcare for the hours the program is open, increasing the opportunity cost of remaining at home for that duration. On the one hand, the theoretical effects on the extensive margin are unambiguously non-negative: the maternal employment rate should not fall and will likely rise. On the other hand, for women who would have otherwise been working, the theoretical effect on hours worked is ambiguous. For women who would have worked fewer hours without the subsidy, there are income and substitution effects that work in opposite directions. For women who would have worked more hours, there is a pure income effect; hours worked should fall. Thus, it is theoretically possible for an evaluation to find positive effects on maternal employment rates, but negative effects on average hours worked in the population of mothers at large.

A static labor supply framework also provides insight into the labor supply effects of leave policy reforms. For example, consider an increase in the income replacement rate under a leave policy, such as those studied in Asai (2015) in Japan and Geyer, Haan, and Wrohlich (2015) in Germany. By providing more non-labor income, such an increase should generate an unambiguous reduction in maternal LFP and employment for the duration of the leave (i.e., it should generate greater take-up of leave). But as discussed above, maternal leave policies exist in the service of making it easier for new mothers to return to the labor force over the longer term. If this is the case, longer-term or more dynamic maternal labor force outcomes, like job 
continuity or labor force participation after the period of leave or income replacement ends, are also of great interest. ${ }^{9}$

\subsection{Contextual Factors}

Regardless of the policy in question, a variety of contextual factors are likely to be important moderators of policy effects. That is, even if the policies were identical, we should not expect that their effects on female labor supply would be the same. Simply put, countries are different along numerous other dimensions that could substantially strengthen or dampen policy effectiveness. The standard static labor supply framework can accommodate various contextual factors, either through the budget constraint governing the tradeoff between leisure and consumption or through maternal preferences.

To take an example on the constraint side, consider the maternal labor supply effects of universal kindergarten programs (for 5-year-olds) in the United States, which have been wellstudied (Gelbach, 2002; Cascio, 2009; Fitzpatrick, 2012). As described above (Tables 2 and 3), the United States is not particularly generous in terms of subsidizing childcare for children under the age of 5 . Further, single mothers have less non-labor income than married or cohabiting ones. It is therefore not surprising that studies of universal kindergarten programs in the United States have tended to find the largest effects for single mothers whose youngest child is age 5; it is precisely for these mothers that the childcare subsidy implicit in universal kindergarten has the most "bite" in terms of lowering childcare costs. Similarly, Simonsen (2010) finds that the female labor supply response to changes in price and access to childcare is

\footnotetext{
${ }^{9}$ Relatedly, Lalive and Zweimeuller (2009) consider the fertility effects of an expansion and later contraction of leave in Austria, and Ruhm (1998) considers the impacts of leave programs on women's relative wages.
} 
statistically significant only 6-13 months after childbirth in Denmark, which is the age during which paid leave is still available and families gradually take up childcare.

By extension, contextual factors should matter for heterogeneity in program effects not just within countries, but also across them. For example, consider the introduction of a universal preschool program. In countries that already have a policy of generously subsidizing childcare, the reduction in childcare costs associated with the introduction of universal preschool would be much lower than in those countries that did not have generous childcare subsidies. Consequently, we would expect there to be less of an effect on female LFP in countries with existing generous childcare subsidies. This is just one way in which the policies can potentially interact with one another and with high female LFP, as posited above.

But other contextual factors should matter for policy effects as well. Continuing with the above example, when implemented in a country where mothers have substantial non-labor income - either through a partner's earnings or through a strong social safety net - the same childcare subsidy or universal preschool program should have less of an effect on maternal labor supply. Wages likely matter, too. If women garner low wages in the labor market, even free childcare, either through cash subsidies or through preschool, may not provide sufficient incentive to work. Similarly, in countries with stronger traditional gender roles, a given policy change may also be less effective because mothers have a higher willingness to pay to remain at home.

Each of the articles in the Special Section pays special attention to interpreting its estimates in light of contextual factors such as these. While comparing across studies is somewhat 
fraught, the studies considered collectively provide valuable insight into the various contextual factors that make family policy more or less effective. We return to this issue in the conclusion.

\section{Overview of the Special Section Articles}

We discuss the Special Section articles by policy. We first consider those that evaluate leave policies, including one on Japan and one on Germany. We then consider those that reduce the cost of childcare through childcare subsides and preschool policies, including papers on France, the Netherlands, Spain, and Canada.

\subsection{Articles on Leave Policies}

The Special Section includes two articles that evaluate the impacts of changes in leave policies, Asai (2015) on Japan and Geyer, Hahn, and Wrohlich (2015) on Germany. A key aspect of these papers' contributions is their focus on reforms that changed income replacement rates under leave policies while the duration of support payments was either held constant or reduced. By contrast, much of the seminal work on leave policies has focused on the effects of changing the duration of paid leave (Ruhm, 1998; Baker and Milligan, 2008; Lalive and Zweimueller, 2009).

Japan

Asai (2015) evaluates the effect of two increases in the income replacement rates under Japanese leave policy where the duration of paid leave was held constant. Before 1995, mothers were entitled to stay at home with their children until the child turned 1-year-old and to return to work with her previous employer, but were not entitled to any income support payments. The 1995 reform introduced an income support payment through social insurance 
at a replacement rate of $25 \%$ if a mother returned to her previous employer, and the 2001 reform increased this replacement rate to $40 \%$. In terms of the 2014 leave policies listed in Table 1, the length and replacement rate of the Japanese policy is fairly generous (and has subsequently become more generous) compared to the other countries.

Asai (2015) examines how these two changes in the replacement rate affected the probability that a mother stayed with an employer using a differencing framework, based on the birthdates of children affected. Job continuity is an important labor market outcome because of its role in building experience and seniority and because of the low rate of job continuity among Japanese women. In the early 2000 s, less than $30 \%$ of women stayed with the same pre-birth employer one year after child birth. To purge her estimates of other contemporaneous changes in the Japanese economy, she also estimates difference-indifferences models, using changes in the job continuity of two other groups, men and nonchildbearing women, as a basis of comparison.

Asai finds very consistent results across the two reforms and across the two comparison groups and various specification checks: The increased generosity of income support had at most a negligible effect on mothers' job continuity rates. Asai points to several factors to explain this null result, including the lack of childcare in Japan, inflexible work hour options among Japanese employers, and deep-rooted traditional gender roles and work culture in Japan. That is, she hypothesizes that there could be interactions between the policy that she evaluates and other labor market policies and cultural mores, and it is these interactions that explain her (lack of) findings. 


\section{Germany}

Geyer, Haan, and Wrohlich (2015) evaluates the effects of a reform that removed meanstesting for income support under Germany's leave policy while simultaneously lowering the duration of paid leave benefits. Not only does the paper provide compelling estimates of the effects of this leave policy change using a clear and transparent identification strategy, but it also builds a structural model of labor supply useful for benchmarking the actual leave policy change and for simulating the effects of additional changes to childcare policy. This latter exercise endeavors to capture exactly the policy interactions that Asai (2015) posits to exist: the effects of leave policies could be intertwined with the generosity of childcare subsidies.

The leave reform in question took place in 2007. In that year, the German leave program transitioned from one where the income support payment was heavily means-tested to one where the income support payment was based on earnings prior to birth (although the replacement rate is still declining as earnings increase). The duration of paid leave also declined from two years to 12 months for couples and 14 months for sole parents. The expectation, based on insights from a static labor supply framework, was that the reform would have negative effects on maternal employment during a child's first year, particularly among higherearning mothers who would not have had paid leave under the previous policy. Likewise, maternal labor supply during a child's second year was expected to increase, but only for the lower-earning mothers who lost paid leave due to the reform.

Using a straightforward differencing strategy based on the birthdates of affected children and adjusting for season-of-birth effects by using mothers giving birth in an unaffected cohort, the authors find statistically significant evidence that the reform lowered employment during 
the first year of the child's life, and more so among the above-median earners newly eligible for benefits. ${ }^{10}$ Furthermore, they find some evidence consistent with employment being greater in the second year of the child's life, particularly among mothers with below median earnings, whose benefit duration was cut by the reform. Thus, the results are consistent with the increased income support payments inducing women to work less when those payments are available, and subsequently to work more when the payments expire.

There was significant excess demand for childcare in Germany around 2000, and since then, Germany has adopted several laws to increase the availability of subsidized childcare for 1- to 3-year-olds. The authors develop a discrete choice, structural labor supply model, similar to those used in previous empirical studies, in which maternal labor supply is determined by her wage, non-labor income, childcare costs, age of the child, and preferences and is conditioned on her partner's (exogenously taken) behavior. They demonstrate that the structural model can produce estimated maternal employment effects of the leave reforms that are quite similar to those arrived at using the differencing strategy. They then simulate the effects of additionally providing universal access to subsidized childcare.

The findings from this simulation suggest that childcare subsidies have relatively large effects on maternal labor supply. Consistent with the static labor supply predictions outlined above, the reductions in employment during the first year caused by leave policy reforms are cut in half when universal subsidized childcare is additionally adopted, and the increase in employment during the second year is increased by about a factor of four. Interestingly, however, the simulations suggest little interaction between the two policies: The sum of the

\footnotetext{
${ }^{10}$ Importantly, "above median" and "below median" earners are identified in such a way so as not to reflect the endogenous labor supply decision.
} 
employment effects when adopting both policies separately is approximately equal to the total effect of adopting the reforms jointly.

\subsection{Articles on Childcare Subsidies and Preschool}

The Special Section includes two articles that evaluate the labor supply impacts of increases in childcare subsidies (Givord and Marbot, 2015, on France and Bettendorf, Jongen, and Muller, 2015 , on the Netherlands), one article that evaluates the labor supply effects of extending universal preschool (Nollenberger and Rodríguez-Planas, 2015, on Spain), and one comprehensive evaluation of a large reform in Québec, Canada that essentially did both (Haeck, Lefebvre, and Merrigan, 2015).

France

Givord and Marbot (2015) evaluates a 2004 policy reform in France that markedly increased the childcare subsidy provided to families for children under the age of 3 , but also temporarily induced variation in eligibility across families with similarly aged children as it was introduced. Using a compelling difference-in-differences strategy to exploit this variation and high-quality administrative data, the authors find that this reform reduced childcare expenditures by about $50 \%$ on average, yet increased female LFP by around 1 percentage point (around 1.5 percent). This estimate is very precise and stable across specifications that exploit different aspects of policy variation and different comparison groups. Moreover, the authors find that the fraction of families using subsidized childcare increased by more than the increase in labor supply, suggesting that the increase in subsidy caused some families to shift from informal childcare arrangements to subsidized ones. In other words, they find some evidence of that subsidized formal childcare "crowds out" informal childcare. 
The authors end with a useful discussion that puts these rather small effects into context. As noted by the authors and is clear in Figure 1, France had a very high rate female labor force participation before these subsidies increased. Moreover, the net cost of childcare was already reasonably low before the policy was implemented, and the existence of universal preschool for 3-year-olds (and some 2-year-olds) meant that childcare was a fairly short-term concern. Once again, the results suggest that various family policies potentially interact with one another and that the pre-existing rate of maternal LFP matters.

\section{The Netherlands}

Bettendorf, Jongen, and Muller (2015) evaluates a substantial increase in generosity in childcare subsidies that was introduced in the Netherlands in 2005 , which reduced the fees of formal childcare to parents by $50 \%$, expanded subsidies to some informal care environments, and tripled public spending on childcare over the following 5 years. Importantly, the Netherlands simultaneously increased the generosity of tax credits provided to low-wage working parents; this coincident policy change must be considered (and is) when interpreting their evaluation.

Using labor force survey data and a difference-in-differences strategy that takes advantage of the ages of children eligible for the subsidies (12 and below), the authors find that these policy changes increased the labor force participation of women by 2.3 percentage points (or about 3.2\% of the comparison group mean) and increased the average number of hours worked per week by 1.1 hours (or 6.2\%) - larger effects than those found in the French case examined by Givord and Marbot (2015). These increases in female labor supply were nevertheless still relatively small, and came at substantial cost. The authors estimate that the increase in fulltime 
equivalent employees due to these policy changes was about 30 thousand, but given that spending on the group increased by $€ 2.6$ billion, the additional public spending per fulltime equivalent was about $€ 87,000$. These high costs were driven by the fact that much of increased subsidies were paid to women who would have worked under the previous subsidy regime and that the subsidy caused a large shift from informal to formal childcare ("crowd out"). Spain

Nollenberger and Rodríguez-Planas (2015) evaluates the adoption of universal fulltime preschool for three year olds during the 1990s in Spain. At the time of the policy change, childcare for children ages 0 to 3 was "rather scarce, predominantly private, and also quite expensive" (p. XXX), whereas enrollment in preschool for 4- and 5-year-olds was well over 90\%. As appropriately stressed in the article's title, the Spanish policy changes were also an interesting case because maternal employment is much lower than the countries that had been typically studied in the past and in the Special Section (France and the Netherlands). Indeed, even in 2000 , at the end of these expansions, the relative female employment in Spain was 10 to $15 \%$ lower than many of the countries where previous evaluations had occurred (see Figure 1).

Using a difference-in-differences strategy that exploits variation in the timing of the policy's introduction across states (with some results further using mothers with other-aged children as an additional comparison group) and labor force survey data, the authors find that the introduction of universal preschool for 3-year-olds increased the LFP rate of mothers with 3year-old children by about 3 percentage points (or about 10\%). The authors further show evidence that these effects persist as the child ages-there continues to be higher maternal 
labor force participation when the children move on to preschool-and that this take-up of universal preschool is not simply replacing informal childcare. The article concludes with a useful detailed discussion that compares the results with those from other countries and describes the policy's costs.

\section{Canada}

Finally, Haeck, Lefebvre, and Merrigan (2015) provides a comprehensive evaluation of the well-known and well-studied Québec, Canada policy of providing childcare at $\$ 5 /$ day for all children 0 to 5 years old. This article is unique in that it evaluates the long-term effects of the policy, considers effects both on mothers and children, and must wrestle with the existence of numerous other articles that have evaluated the same policy. It offers a fitting conclusion to the compelling collection of articles in the Special Section.

Haeck, Lefebvre, and Merrigan draw several important conclusions based on their (and that of others) empirical work. First, using the rest of Canada as a comparison group in a differencein-differences framework, they conclude that the policy greatly increased the use of childcare, both on the extensive and intensive margins. Second, they conclude that the policy had "large, significant, and persistent" effects on maternal labor supply, particularly for highly educated mothers. Not only do they credit these effects to the low cost of childcare associated with the policy, but also credit a large expansion of formal childcare spaces and a robust Canadian economy. Third, they conclude that the policy reduced the cognitive development of the children ages 4 and 5 of low-educated mothers. They suggest this finding is likely driven by the actual implementation process, which led to children being in daycare an increased number of hours and the expanded spaces providing "at best average quality care" (p. XXX). 


\section{Conclusion}

While all of the national studies in the Special Section have made use of specific policy variation to isolate the effect of an individual policy change on female labor force participation, the resulting effects range from rather small (Asai, 2015; Givord and Marbot, 2015) to rather large (Haeck, Lefebvre, and Merrigan, 2015; Geyer, Haan, and Wrohlich 2015). In each case, the authors discuss the national context in which the policy was adopted, thereby providing richer insight into why the various effects were observed. For example, two articles explicitly suggest that the scope for policy to increase labor supply is somewhat limited by the country having a previously high rate of female labor force participation (Givord and Marbot, 2015; Bettendorf, Jongen, and Muller, 2015). Two other articles note that, despite the fact that female labor force participation was initially relatively low, the lack of other supportive policies (leave policies by Nollenberger and Rodríguez-Planas, 2015; childcare poclies by Asai, 2015) can limit a policy's effects. Several articles explicitly discuss the possibility that social norms are important to understanding the effects (Asai, 2015; Givord and Marbot, 2015; Nollenberger and Rodríguez-Planas, 2015). ${ }^{11}$

While such interactions between various policies, societal factors, and economic factors can be difficult to capture directly using a quasi-experimental strategy—only so much policy variation exists within any one country-it is important to remember that such interactions are potentially very important and should be taken into account in the interpretation of studies. Moreover, the potential for such interactions make the modeling exercise in Geyer, Haan, and Wrohlich (2015) even more useful because, to the extent that a structural model can

\footnotetext{
${ }^{11}$ Dahl, Løken and Mogstad (2014) and Ciliberto, Miller, Nielsen and Simonsen (2015) explicitly address the issue of such social interaction effects.
} 
reasonably capture the labor supply decisions that are being made, such interactions can be examined directly.

A closely related issue is crowd-out: To what extent does the increased provision of, say, subsidized formal childcare displace other childcare arrangements? In other words, what is the counterfactual care arrangement? Again, three articles are set in national contexts with relatively low female labor force participation (Asai, 2015; Haeck, Lefebvre, and Merrigan, 2015; Nollenberger and Rodríguez-Planas, 2015) and two others are set in contexts where initial female labor force participation is relatively high (Givord and Marbot, 2015; Bettendorf, Jongen, and Muller, 2015). Clearly, the scope for crowd-out is much higher in the latter context, and indeed, both of those papers discuss the relatively high apparent costs of increasing maternal labor force participation.

In light of such crowd-out, we believe two points should be kept in mind. First, this crowdout still represents an income transfer to those mothers who would have otherwise worked, and these income transfers could affect other outcomes such as the quality of childcare (Haeck, Lefebvre, and Merrigan, 2015), child outcomes (Haeck, Lefebvre, and Merrigan, 2015; see Ruhm and Waldfogel, 2012, for a useful review), and, more generally, consumption. A full evaluation of the effect of family policies should take such effects into account as well.

Second, even if policy effects on other such outcomes are absent, these family support policies could still be judged to be valuable on social insurance grounds. Quite simply, the marginal utility of consumption and leisure could be quite high around the time of childbearing. Such family support policies might be an efficient mechanism to redistribute income across time and people to support parents around the time of childbirth Although economists often 
hesitate to specify social welfare functions when evaluating policies, it need not be the case that policy makers are ignoring them.

Up to this point, we have focused on the potential effects of these policies on decisions that families make. A complete analysis should also consider the potential effects on labor demand. And along this dimension, perhaps the effects of the policies are not as favorable for women. It is quite possible that extended leave could be viewed as disruptive by some firms because an employee is allowed to step away from her duties for a period of time, but then must be reintegrated into the workplace at a substantially later date. To the extent that firms view such leave as negatively affecting productivity, they may be less likely to hire or promote those individuals who are profiled to be most likely to take leave or relegate such individuals to lower positions. Relatively few studies have tried to link family policies directly to labor demand outcomes. However, such mechanisms could contribute to the so-called "glass ceiling" at the top of the labor market in the Nordic countries (Albrecht, Thoursie, and Vroman, 2014) and limit the opportunity for females to reach top corporate positions (Smith, Smith, and Verner, 2013).

Finally, we do want to make an observation about the value of the papers as a collection. Each study is a thorough investigation of a policy in a single country, and because of this focus on a single country, each study provides a complete description of the policy environment, uses high-quality and country-specific data, and provides compelling estimates. At the same time, we believe that the value of the collection of articles is greater when they are taken together. While we caution a reader from comparing the results too directly (the policies often differ in key ways and the contextual environments differ along numerous dimensions), we believe 
some more general conclusions are available, as described above. That is why we chose to pursue this path of publication for these articles, and that is why we provide this integrative discussion. We hope you will read the individual articles and judge for yourself. 


\section{References}

Albrecht, James, Peter Skogman Thoursie and Susan Vroman. 2015. "Parental Leave and the Glass Ceiling in Sweden." Research in Labor Economics 41:89-114.

Asai, Yukiko. 2015. "Parental leave reforms and the employment of new mothers: Quasiexperimental evidence from Japan." Labour Economics XXX.

Baker, Michael and Kevin Milligan. 2008. "How does Job-Protected Maternity Leave Affect Mothers' Employment?" Journal of Labor Economics 26(4):655-691.

Bettendorf, Leon J.H., Egbert L.W. Jongen, and Paul Muller. 2015. “Childcare subsidies and labour supply - Evidence from a Dutch reform." Labour Economics XXX.

Cascio, Elizabeth U. 2015. "The promises and pitfalls of universal early education." IZA World of Labor: Evidence-Based Policy Making 116:1-10.

Cascio, Elizabeth U. 2009. "Maternal Labor Supply and the Introduction of Kindergartens into Public Schools." Journal of Human Resources 44(1):140-170.

Cascio, Elizabeth U. and Diane Whitmore Schanzenbach. 2013. "The Impacts of Expanding Access to High-Quality Preschool Education." Brookings Papers on Economic Activity 2013(Fall):127-178.

Ciliberto, Federico, Amalia R. Miller, Helena S. Nielsen and Marianne Simonsen (2015) “Playing the Fertility Game at Work: An Equilibrium Model of Peer Effects" Forthcoming in International Economic Review.

Dahl, Gordon B., Katrine V. Løken and Magne Mogstad. 2014. "Peer Effects in Program Participation." American Economic Review 104(7): 2049-74. 
Fitzpatrick, Maria D. 2012. “Revising Our Thinking about the Relationship between Maternal Labor Supply and Preschool." Journal of Human Resources 47(3):583-612.

Gelbach, Jonah. 2002. "Public Schooling for Young Children and Maternal Labor Supply." American Economic Review 92(1):307-22.

Geyer, Johannes, Peter Haan, and Katharina Wrohlich. 2015. "The effects of family policy on maternal labor supply: Combining evidence from a structural model and a quasiexperimental approach." Labour Economics XXX.

Givord, Pauline and Claire Marbot. 2015. "Does the cost of child care affect female labor market participation? An evaluation of a French reform of childcare subsidies." Labour Economics XXX.

Haeck, Catherine, Pierre Lefebvre, and Philip Merrigan. 2015. “Canadian evidence on ten years of universal preschool policies: The good and the bad." Labour Economics XXX.

Lalive, Rafael and Josef Zweimuller. 2009. "How Does Parental Leave Affect Fertility and Return to Work? Evidence from Two Natural Experiments." Quarterly Journal of Economics 124(3):1363-1402.

Nollenberger, Natalia and Nuria Rodríguez-Planas. 2015. "Full-time universal childcare in a context of low maternal employment: Quasi-experimental evidence from Spain." Labour Economics XXX.

OECD. 2014. "PF3.4: Childcare support." OECD Family Database. OECD-Social Policy DivisionDirectorate of Employment, Labour and Social Affairs. 1 May 2015. 
OECD. 2015. "PF2.1: Key characteristics of parental leave systems." OECD Family Database. OECD-Social Policy Division-Directorate of Employment, Labour and Social Affairs. 12 May 2015.

Ruhm, Christopher. 1998. "The Economic Consequences of Parental Leave Mandates: Lessons from Europe." Quarterly Journal of Economics 113(1):285-317.

Ruhm, Christopher and Jane Waldfogel 2012. "Long-Term Effects of Early Childhood Care and Education." Nordic Economic Policy Review 1:23-51.

Simonsen, Marianne. 2010. "Price of High-quality Daycare and Female Employment." Scandinavian Journal of Economics 112(3):570-94.

Smith, Nina, Valdemar Smith and Mette Verner. 2013. "Why are so few Females Promoted into CEO and Vice President Positions? Danish Empirical Evidence, 1997-2007. "Industrial Labor Relations Review 66(2):380-408. 
Figure 1: Ratio of Female to Male LFP for 25-54 Year-Olds for Select OECD Countries, 2000-2014

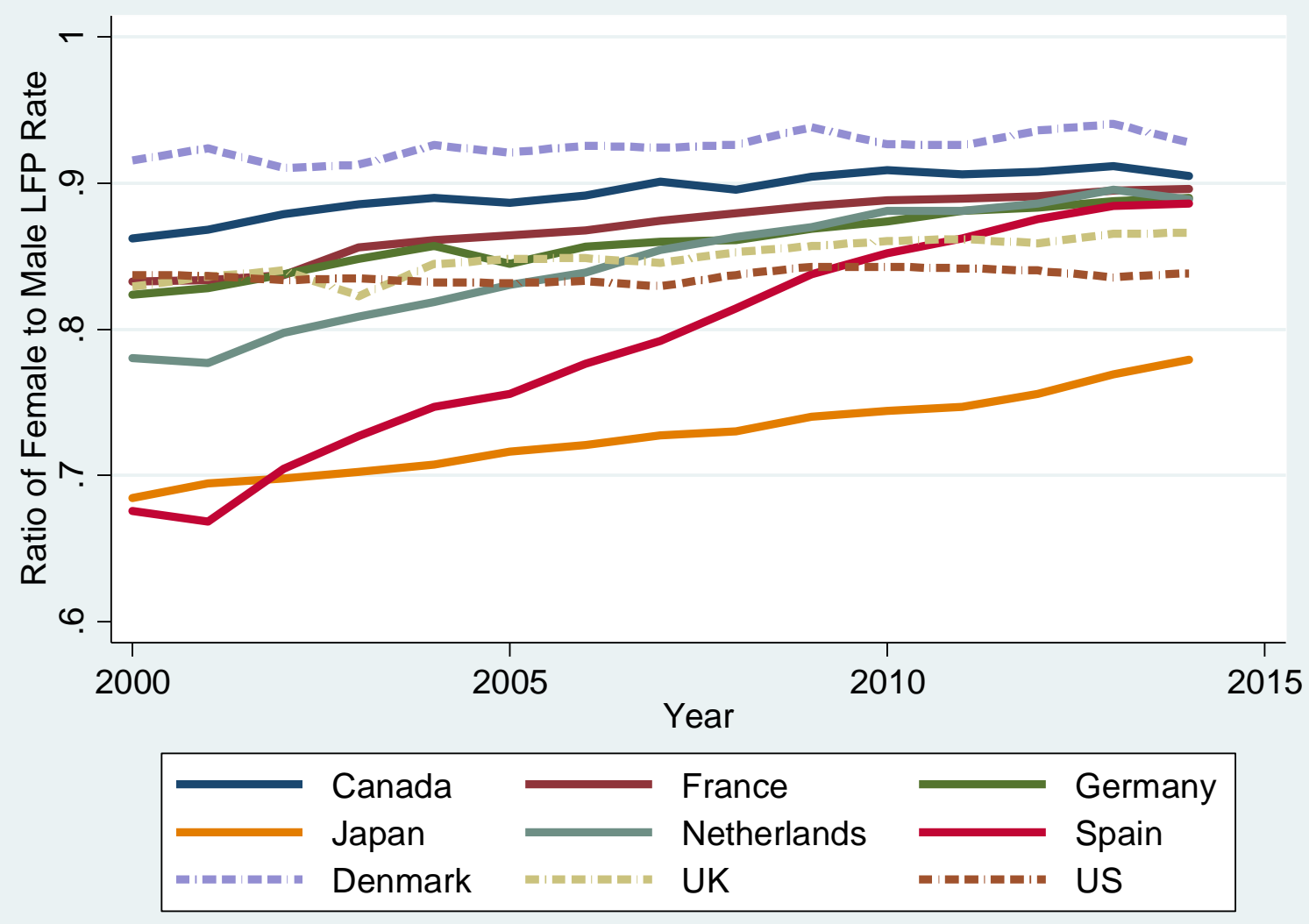

Notes: Authors' tabulations based on OECD labor force participation data (downloaded 9 July 2015). 
Table 1: Paid Leave Policy in Selected OECD Countries, 2014

\begin{tabular}{|c|c|c|c|c|c|c|}
\hline & \multicolumn{6}{|c|}{ Paid leave and home } \\
\hline & \multirow{2}{*}{\multicolumn{2}{|c|}{ Paid maternity }} & \multicolumn{2}{|c|}{ care leave available to } & \multicolumn{2}{|c|}{ Paid leave reserved for } \\
\hline & & & \multicolumn{2}{|c|}{ mother } & \multicolumn{2}{|c|}{ father } \\
\hline & & Replacement & & Replacement & & Replacement \\
\hline & Weeks & rate & Weeks & rate & Weeks & rate \\
\hline OECD Average & 17.0 & 77.7 & 36.6 & 45.8 & 9.0 & 64.2 \\
\hline \multicolumn{7}{|l|}{ Special Section } \\
\hline \multicolumn{7}{|l|}{ Countries } \\
\hline Canada & 17.0 & 47.7 & 35.0 & 54.0 & 0 & 0 \\
\hline France & 16.0 & 100.0 & 26.0 & 18.4 & 28.0 & 24.2 \\
\hline Germany & 14.0 & 100.0 & 44.0 & 47.0 & 8.7 & 47.0 \\
\hline Japan & 14.0 & 67.0 & 44.0 & 59.9 & 52.0 & 58.4 \\
\hline Netherlands & 16.0 & 100.0 & 26.0 & 18.1 & 26.4 & 19.3 \\
\hline Spain & 16.0 & 100.0 & 0 & 0 & 2.1 & 100.0 \\
\hline \multicolumn{7}{|l|}{ Other Countries } \\
\hline Denmark & 18.0 & 53.3 & 32.0 & 53.3 & 2.0 & 53.3 \\
\hline United Kingdom & 39.0 & 30.9 & 0 & 0 & 2.0 & 20.2 \\
\hline United States & 0 & 0 & 0 & 0 & 0 & 0 \\
\hline
\end{tabular}


Table 2: Net Monthly Childcare Costs as a Fraction of Earnings in Selected OECD Countries, 2012

\begin{tabular}{lcc}
\hline & $\begin{array}{c}\text { Dual-earner family } \\
\text { with full-time } \\
\text { earnings } 150 \% \text { of the } \\
\text { average wage }\end{array}$ & $\begin{array}{c}\text { Sole-parent family } \\
\text { with full-time } \\
\text { earnings of } 50 \% \text { of } \\
\text { the average wage }\end{array}$ \\
\hline OECD Average & 17.1 & 9.8 \\
Special Section Countries & & \\
Canada (Ontario)* & 31.2 & 35.3 \\
France & 13.1 & 2.4 \\
Germany (Hamburg) & 11.2 & 1.9 \\
Japan (Tokyo) & 21.7 & 15.6 \\
Netherlands & 23.5 & 6.3 \\
Spain & 7.9 & 7.9 \\
Other Countries & & 0 \\
Denmark & 11.9 & 3.7 \\
United Kingdom (England) & 45.0 & 31.6 \\
United States (Michigan) & 39.7 & 0 \\
\hline Notes: The costs come from & & \\
\hline
\end{tabular}

Notes: The costs come from OECD Family database (Charts PF3.4.B and PF3.4.C). The table shows formal childcare costs for two children that are aged 2 or 3 years old, net of benefits, rebates and tax concessions, and other relevant benefits.

* Québec introduced \$5/day universal childcare for children ages 0 to 5. 
Table 3: Formal Fulltime Childcare and Preschool Enrollment Rates, around 2010

\begin{tabular}{|c|c|c|c|c|}
\hline & \multirow[b]{2}{*}{ Policy (ages) } & \multicolumn{3}{|c|}{ Fulltime enrollment by age (\%) } \\
\hline & & 3 years & 4 years & 5 years \\
\hline OECD Average & -- & 63.0 & 82.4 & 92.1 \\
\hline \multicolumn{5}{|c|}{ Special Section Countries } \\
\hline Canada* & Universal preschool (5) & 6.2 & 32.2 & 89.7 \\
\hline France & Universal preschool (3-5) & 100 & 100 & 100 \\
\hline Germany & Universal childcare (1-5) & 88.0 & 96.5 & 96.9 \\
\hline Japan & None & 75.8 & 96.1 & 98.5 \\
\hline Netherlands & Universal preschool (4-5) & 28.3 & 99.5 & 99.3 \\
\hline Spain & Universal preschool (3-5) & 98.3 & 99.4 & 100.0 \\
\hline \multicolumn{5}{|l|}{ Other Countries } \\
\hline$\overline{\text { Denmark** }}$ & Universal childcare (0-5) & 96.7 & 97.9 & 87.8 \\
\hline United Kingdom & None & 83.0 & 97.9 & 99.4 \\
\hline United States*** & None & 47.1 & 68.4 & 84.2 \\
\hline
\end{tabular}

Notes: Policy information comes from the Special Section papers and sources therein and Cascio (2015). Enrollment information comes from OECD Family Database (Table PF3.2.A). The enrollment information includes enrollment in childcare and preschool programs. The fulltime rates are computed as fulltime equivalents, where fulltime care is assumed to be 30 hours/week.

* Universal childcare is provided in Québec for children 0-5.

** The decline from 4 to 5 years is explained by the transition to school.

*** In the US, universal preschool is not offered federally, but some locales do (notably, the states of Georgia and Oklahoma and the city of Boston). Programs exists that are targeted at poor families (e.g., Head Start) 